\title{
De un vistazo
}

\section{Dieta mediterránea, estilo de vida y mortalidad en hombres y mujeres Europeos. El Proyecto HALE (JAMA, 2004:1433-39)}

Los patrones dietéticos y el estilo de vida están asociados la con mortalidad por varias causas, especialmente por enfermedad arterial coronaria, enfermedades cardiovasculares, y cáncer. Este estudio investiga el efecto simple o combinado de la dieta medite-rránea, la actividad física, el consumo moderado de alcohol y el no fumar sobre causas totales y causas especificas de mortalidad en ancianos mayores de 70 años en 11 países de Europa seguidos durante diez años. Durante el seguimiento de un total de 1507 hombres y 832 mujeres, faIlecieron 935 participantes, 371 por enfermedad cardiovascular, 233 por cáncer y 145 por otras causas (de 186 se desconoce la causa de la muerte). La adherencia a la dieta mediterránea, el uso moderado de alcohol, la actividad física y el no fumar se asociaron con un bajo riesgo de mortalidad por todas las causas y resultados similares se observaron en la morta-lidad cardiovascular, coronaria o por cáncer. En total, la falta de adherencia a este patrón de bajo riesgo fue asociado con un riesgo poblacional atribuible* del $60 \%$ para todas las causas de muerte, $64 \%$ de muerte por enfermedad coronaria, $61 \%$ por enfermedad cardiovascular y $60 \%$ por cáncer. Los participantes con dietas y estilo de vida más saludables tuvieron, el más bajo riesgo de todas las causas de mortalidad y de mortalidad por causas especificas. En este estudio el 60 al $64 \%$ de la mortalidad estuvo relacionada a una baja adherencia al patrón de bajo riesgo. Esto avala la hipótesis que los participantes que siguieron una dieta tipo mediterránea con hábitos de vida saludables tenían menos posibilidades de fallecer de todas las causas y de causas específicas aun en edades de 70 a 90 años. Aún son necesarios estudios de intervención para relacionar estos patrones de bajo riesgo con los factores causales de mortalidad, y además se desconoce la cantidad de años que una persona debe mantener estos estilos de vida para que sean beneficiosos. Sin embargo, una dieta mediterránea rica en vegetales y frutas en combinación con no fumar, consumir moderadas cantidades de alcohol y por lo menos 30 minutos de actividad física diaria se asocian con una mejor sobrevida aún en edades avanzadas.

\author{
¿Tiene este paciente una historia familiar de cáncer? Un análisis basado en la evidencia de la precisión de la histo- \\ ria familiar de cáncer. \\ (JAMA 2004; 292:1480-1489)
}

Una historia familiar de determinados canceres está asociada con un riesgo incrementado de desarrollar esta enfermedad. Este estudio utiliza como ejemplo un caso clínico de una paciente de 35 años con antecedentes de la madre con cáncer de mama a los 42 años y la abuela a los 30 años, que consulta porque quiere conocer el riesgo de desarrollar cáncer y a partir de que edad debe realizar control mamográfico. Con esto se plantea como deben recolectarse los datos para obtener la validez en la historia familiar de cáncer. Dos metanálisis encontraron un riesgo relativo de 2,1 (IC95\% 2,0-2,2) para cáncer de mama y 3,1 (IC95\% 2,6-3,7) para cáncer de ovario con familiares afectados de primer grado. Riesgos elevados similares se han notado para el cáncer de endometrio, colon y próstata. Es necesaria una buena recolección de datos familiares positivos para cáncer, ya que una mala recolección de los mismos puede llevar a una sobreestimación del riesgo con la consecuente indicación de procedimientos diagnósticos y cirugías innecesarias. Hasta ahora diferentes estudios sugieren una prevalencia de historia familiar de cáncer estimada en una rango de 5 a 22\% para el cáncer de mama; 2 a 9,4\% para el cáncer de colon; 1,1 al 3,5\% en el de ovario; 0,5 al 1,4 en el cáncer de endometrio y 4,6 al 9,5\% en el de próstata. La variabilidad de estos rangos se debe a la metodología de los estudios poblacionales, a incluir familiares no solamente de primer grado y a si los estudios han sido realizados por centros de referencia en cáncer o centros de genética, en donde se encuentra una prevalencia* más elevada. Este estudio revisó 22 artículos en inglés, excluyendo 8 por reportar solo datos del interrogatorio familiar. Los trabajos revisados reportan datos positivos y negativos para antecedentes de cáncer familiar y se tomó como datos para incluir los trabajos, los antecedentes de cáncer en familiares de primer grado confirmados por antecedentes médicos, certificados de defunción o la verificación con registros de cáncer poblacionales. Esta revisión concluye que la precisión en pacientes que reportan historia familiar de cáncer para familiares en primer grado son confiables y válidas para riesgo de cáncer de mama y colon; no siendo así en los cánceres de ovario y endometrio.

Sergio A Boero [ Médico del Servicio de Clínica Medica, Hospital "Felipe Glasman" Bahia Blanca. ]

* ver glosario

\section{Retiro del mercado de la pemolina}

Informamos a nuestros lectores que la que la Administración de Drogas y Alimentos de EEUU (FDA) decidió retirar del mercado los productos que contienen pemolina.

Esta decisión se respalda en la evaluación de que los riesgos de hepatotoxicidad (21 casos, 13 de ellos condujeron a transplante hepático y/o muerte) superan los potenciales beneficios.

Esta droga se utilizaba como segunda línea en el tratamiento del trastorno por déficit de antención e hiperactividad, por lo que recomendamos a los profesionales que la indicaban, que la reemplacen por otro fármaco.

Es interesante destacar que en 1996 y 1999 la FDA había resuelto la incorporación de una advertencia en la etiqueta sobre el riesgo de hepatotoxicidad y sobre la necesidad de monitoreo de la función hepática. Sin embargo, una evaluación realizada en 2002 demostró que la medida no había tenido impacto respecto del incremento del moninotereo ni de la promoción del uso de pemolina sólo como droga de segunda línea.

C E T OX [ Centro de Emergencias Toxicológicas Hospital Italiano ]

Buenos Aires

0800-444-4400

cetox@hospitalitaliano.org.ar 